\title{
Review for application of electrospinning and electrospun nanofibers technology in textile industry
}

\author{
Mohammad Mirjalili ${ }^{1} \cdot$ Salar Zohoori $^{1}$
}

Received: 3 November 2015/Accepted: 5 March 2016/Published online: 24 March 2016

(c) The Author(s) 2016. This article is published with open access at Springerlink.com

\begin{abstract}
Electrospinning (electrostatic fiber spinning) is a modern and efficient method which uses electric field to produce fine fibers which their diameter can reduce to nanometers. These fibers have wide applications in industry such as filtration, composite materials, medical, membrane, etc. In this paper a review of electrospinning process, its products and applications are explained.
\end{abstract}

Keywords Electrospinning $\cdot$ Nano fiber $\cdot$ Filtration · Textile $\cdot$ Fiber

\section{History of electrospinning}

The history of electrospinning is traced back to 1902 based on Cooley pattern [1] and Morton [2]. John Zeleny had reported that in 1914 he was working on treatment of liquid drop at the end of iron capillaries. During this study, he tried to find a mathematical model of liquids under electrostatic forces. In the 1930s, Formhals tried to produce electrospun fibers [3-6]. Although it had some disadvantages such as drying system (due to distance between nozzle and collector), he modified the device and improved it in $1940[5,7]$. Sir Geoffrey Ingram Taylor had generated the electro-spinning theoretical underpinning between 1964 and 1969. His research has helped to upgrade the electrospinning by modeling the hopper form which liquid drops were formed by electric field. Also his collaboration with JR Melcher led to expand the "leaky dielectric model" for

Mohammad Mirjalili

dr.m.mirjalili@iauyazd.ac.ir

1 Department of Textile Engineering, Yazd Branch, Islamic Azad University, Yazd, Iran conducting liquids [8-10]. After that in the 1990s Reneker used high voltage to charge the polymer dispersion to produce fibers with diameter of less than $5 \mu \mathrm{m}$ [11-15]. Figure 1 shows a schematic of electrospinning device which contains a reservoir of polymer dispersion with a pump, a high-voltage source, a nozzle and a conductive collector. Based on electrostatic field between nozzle and collector, the polymer solution is collected on the surface of collector screen [16].

\section{Electrospinning process}

Many theoretical researches on electrospinning process have been done by many teams and groups [17-19]. At the end of the 1500s, Sir William Gilbert explained the behavior of electrostatic and magnetic emanation. $\mathrm{He}$ found that by affecting the water droplet by electrostatic field, the water gets cone and hopper shape, and a droplet extrudes from the head of the hopper. This formed the first process of electro-spraying. Electrospinning can be viewed as a kind of electro-spraying. As with electro-spraying, the raw material of electrospinning is linked to a high-voltage power supply to enhance the liquid electrostatic potential. High molecular degree of polymers is always used as raw materials based on their inter-molecular interaction. The surface charge of liquid and electrostatic potential have direct relationship; so by increasing or decreasing one of them, the same action will happen for another one. Usually by surface tension, the volume shape of fluid is deducted. By charging the fluid, the surface charge acts in the reverse manner to surface tension, resulting in the fluid changing shape, forming the structure known as the Taylor cone [8].

Many parameters influence electrospinning of fibers and because of this, the study and research in this field are hard. 
Fig. 1 Different collectors of electrospinning [36]

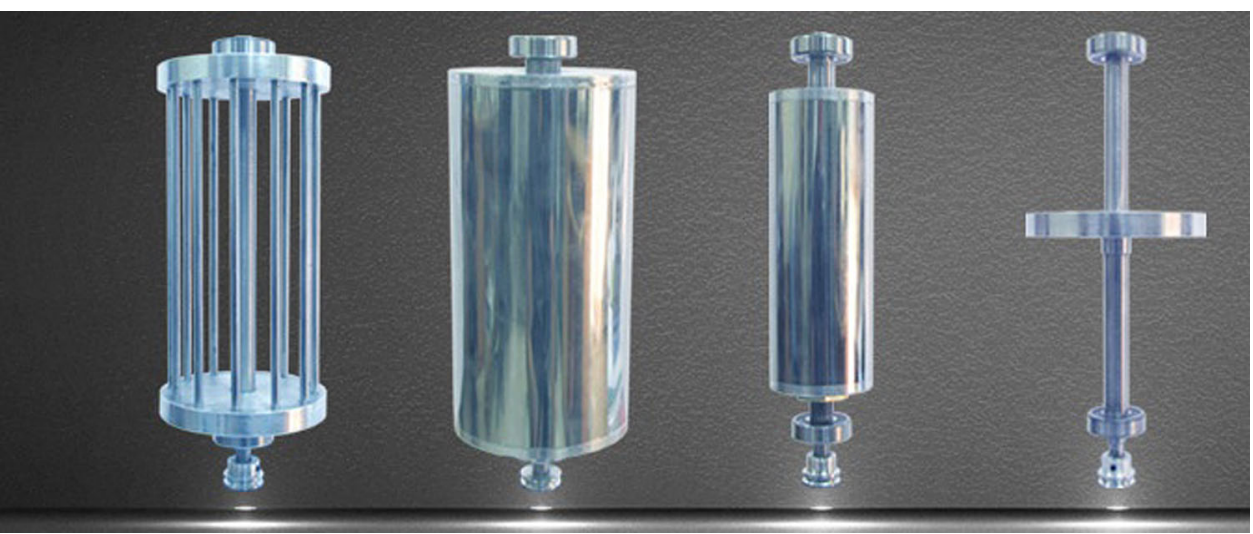

For instance, by increasing $0.25 \mathrm{wt} \%$ of ionic salts, the rate of mass transferring due to a phenomena known as the "virtual orifice" is reduced [20]. In the following, some of these important parameters have been discussed.

\section{Collector}

The physical properties of electrospun fibers (such as crystal morphology and molecular orientation) are affected by the nature of collectors [21-23]. The most commonly used collector is rotating drum collector which is shown in Fig. 1. With this collector (due to drum speed), the diameter of the fiber can be controlled [24, 25]. Rotating disk is used for creating uniaxial aligned fibers. The most important benefit of using disk collector instead of drum collector is that large number of the fibers are residue on the disk edge and the aligned fibers are gathered as nano fibers [2630]. Another kind of collectors is using two or more parallel electrodes so that excellent alignment can be obtained on each electrode based on air holes through the electrodes that cause electrostatic rebuttal between the fibers [31-33]. Fibers (isotropic/anisotropic) are affected by speed and type of collector disc or drum. The speed of collector can improve the crystal orientation of fibers due to polymer molecular chains' alignment in the direction of fiber axis which is obtained due to the force of rotational speed of collector [34]. It must be mentioned that using high-speed rotational collector can cause create ventilator effect and evaporation of solvent [35].

\section{Applied voltage}

The applied voltage in electrospinning has an important duty in ultimate fiber characterization. The forwarding of charge in electrospinning is because of polymer flow towards the collector and the polymer mass flow from the nozzle has direct effect on decreasing or increasing the current.
Increasing the voltage can cause increase in the spinning current [37]. Increasing spinning current can lead to incidence of beaded morphology, and this structure can reduce the surface area. Increase or decrease in applied voltage can cause change of morphology and structure of fibers [37]. The study shows that the increase in voltage leads to increase in fiber length and decrease in fiber size [38-40].

\section{Distance between nozzle-collector}

The other parameter that has affected morphology, structure, physical and chemical properties of electrospun fibers is the distance between nozzle and collector. It has the direct effect on final fiber properties based on evaporation rate, deposition time and inconsistency interval. The studies show that by decreasing the distance between nozzle and collector, we have wet electrospun fiber which has beaded structure. Also in some fibers the morphology of final fibers has changed from circular shape to flat shape [38, 40]. On the other hand, the study shows that for aqueous polymer dispersion, more distance is needed to dry the fiber [40].

\section{Dispersion flow rate}

The other effective parameters on physical and chemical properties of produce fiber is polymer flow rate. Change in the rate of polymer flow (from the syringe of electrospinning device) causes change in fiber morphology. By increasing the flow rate, the diameter of the fiber is increased and beaded morphology is observed [38, 41-43].

\section{Electrospun products}

Based on electrospun special characters such as diameter, production process and fiber filament, these fibers have received much attention for use in many applications. 
Table 1 Comparision the different method of producing nano fiber

\begin{tabular}{|c|c|c|c|c|}
\hline Process & $\begin{array}{l}\text { Can the process } \\
\text { be scaled }\end{array}$ & $\begin{array}{l}\text { Control on fiber } \\
\text { dimensions }\end{array}$ & Advantages & Disadvantages \\
\hline Drawing & $x$ & $x$ & Minimum equipment requirement & Discontinuous process \\
\hline Self-assembly & $x$ & $x$ & Good for obtaining smaller nano fibers & Complex process \\
\hline Phase separation & $x$ & $x$ & $\begin{array}{l}\text { Minimum equipment requirement. Process can } \\
\text { directly fabricate a nanofiber matrix. Batch-to- } \\
\text { batch consistency is achieved. Mechanical } \\
\text { properties of the matrix can be tailored by } \\
\text { adjusting polymer concentration }\end{array}$ & $\begin{array}{l}\text { Limited to specific } \\
\text { polymers }\end{array}$ \\
\hline Template synthesis & $x$ & $\boldsymbol{\sim}$ & $\begin{array}{l}\text { Fibers of different diameters can be easily achieved } \\
\text { using different templates }\end{array}$ & - \\
\hline Electrospinning & $\boldsymbol{\nu}$ & $\boldsymbol{\sim}$ & $\begin{array}{l}\text { Cost effective. Long, continuous nanofibers can be } \\
\text { produced }\end{array}$ & Jet instability \\
\hline
\end{tabular}

Some of the more active areas of application are composite fibers, carbon nano tubes, inorganic fibers and tissue scaffolds. In composite electrospun fibers, preparing polymer dispersion of different material is very simple. Therefore, it is possible to produce various fibers with their own and new characteristics [44-49]. Producing inorganic fibers with nano diameter is not easy. Table 1 compares the different methods of producing nano fiber. The usual method is coating the electrospun matrix with inorganic materials by chemical sinter [50]. One of the usages of electro-spun fibers is tissue scaffolding. The porosity and high surface area of the nonwoven electrospun mat causes development of tissue scaffolding. It has free area between the fibers with a scale of length to cell size about $1-10 \mu \mathrm{m}$ [51]. In 2006, Ohkawa et al. reported the electro-spinning of natural polymer chitosan [52]. Also, Schiffman et al. showed Schiff base cross-linked chitosan mats using electrospinning which achieved more faster [53]. On the other hand, regenerated fibroin of silk dispersion in formic acid has been electrospun by Min et al. whose fibroin consists of a quarter alanine and $42 \%$ glycine [54]. Soffer et al. also electrospun nonwoven nanofibers from Bombyx mori silk fibroin using aqueous process. Mechanical characterization tests show fantastic results [55]. Many authors studied and reported about electrospinning of collagen (one of most usual proteins) from 1,1,1,3,3,3-hexafluoro-2-propanol [56-59], but Zeugolis et al. report that most of its properties were lost during electrospining from 1,1,1,3,3,3hexafluoro-2-propanol or 2,2,2-trifluoroethanol [60]. Li et al. reported about gelatin-elastin-PLGA electrospun composite and they succeed to produce it with a diameter of $380 \mathrm{~nm}$ so that it can apply as tissue [61]. Also electrospun nanofibers of gelatin-hydroxyapatite were produced by Kim et al. for guided tissue engineering [62, 63].

\section{CNT}

Carbon nano tubes (CNT) have several mechanical characteristics such as a high modulus and high tensile strength [64-67]. When the carbon nano tubes are used as reinforcement in composite, it is so hard to string them and this is a disadvantage of CNTs. This nanocomposite cannot envisage mechanical properties that was thought. Therefore many researches have been done to synthesize CNTs into polymer nano fibers produced by electro-spinning method [68, 69]. The process of electrospinning is expected to string the CNTs from one end of fiber to the other based on opposite conductivity of polymer dispersion and sheer force of electrospinning [69]. Jiang et al. reported that by electrospinning of carbon nanotube/polyaniline, great application foreground in electrochemical energy field was achieved based on large current response, high conductivity and specific capacity [70]. Also Maitra et al. reported that by electrospinning of CNT/PAN, the conductivity of fiber increases and the impression of fabrication method on the arrangement of carbon sheets in electro-spun nano fibers was investigated and a templating effect by CNTs that leads to increased graphitization was suggested [71]. Electrical conductance mensuration on electrospun nano fiber showed an electrical infiltration threshold around 2 wt\% multiwall CNTs, which was reported by Mazinani et al. [72]. Further, Rana et al. showed that electrospinning of poly-urethane (PU) core and composites sheath with multiwall CNTs is very impressive for increasing the physical properties of nano fiber. Also, the results show that the product has rapid form restoration, contrast with that of pure shape memory PU and PU/ MWNTs [73]. 


\section{Fiber alignment}

Fibers in nano scale were almost achieved by nonwoven techniques and they had no more applications and it was limited to filtration [74, 75], implant coating film [40], tissue [76] and wound dressing [77]. Aligned micro-fibers are of specific attention to nerve-tissue engineering based on the size and diameters of axons and myelinated nerve fibers [78-80]. One way to acquire aligned electrospun fibers is to sediment fibers on a rotationally, electrically grounded wheel keen edge [81]. The wheel with a sharpened is spun at a stable angular speed. The fiber flow is extruded such that the fibers align parallel and over the keen edge. This method includes a proportion plain arrangement and can produce aligned fibers, but the uttermost fiber diameter are restricted to the little area surrounding the rotating side [33]. Next uniaxial aligned fiber deposition target includes double magnetic pole, and the electro-spinning dispersion is entrusted in the area covering the magnetic poles. This method can produce highly aligned fibers at inter-electrode distances of till $1 \mathrm{~mm}$, however, the efficiency of fiber is limited because the fiber alignment area is surrounded by the orthogonal edges of the electrodes. Also, alignment typicality reduces with inter-electrode distances greater than $1 \mathrm{~mm}$ [82].

\section{Wound dressing}

Electrospinning could generate a platform to protect wounds. The studies show that using electric field the ultrafine nano fibers can be directly spun on to the injured place of skin to form a fibrous mat dressing [77, 83] (Fig. 2). These nano fibers which have pore size between 500 and $100 \mu \mathrm{m}$ are suitable for protecting the wounds from bacteria. Many kinds of polymers such as carboxyethyl chitosan/PVA [84], collagen/chitosan [85], Silk fibroin [54],

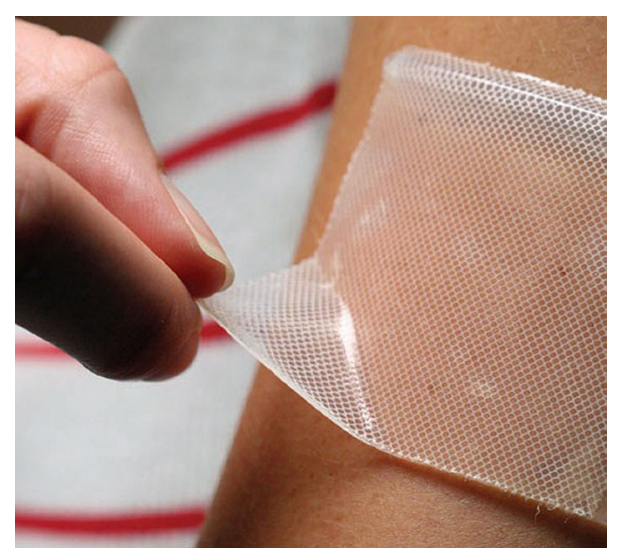

Fig. 2 Wound dressing by electrospinning [36] and ABA type poly(dioxanone-co-L-lactide)-block-poly(ethylene glycol) (PPDO/PLLA-b-PEG) block copolymer [86] have been electrospun and suggested for wounddressing usages. Hong reported that he prepared electrospinning wound dressing of PVA/ $/ \mathrm{AnNO}_{3}$ and treated the webs by ultraviolet or by heating [87]. As reported, Duan et al. have also made antibacterial electrospinning nano fibers of poly( $\varepsilon$-caprolactone) (PCL) with little nano particles of silver-loaded zirconium phosphate (nano $\mathrm{AgZr}$ ) for potential use in wound dressing usage. The outcome demonstrates that the electrospun fibers still have antibacterial properties [88]. Also, Kim et al. have explained an electro-spinning device that uses a guiding air blowing system and electrode to enable the production of wound dressing cover of poly( $\varepsilon$-caprolactone) nano fibers [89]. Further, Ignatova et al. reported that electrospinning of poly-vinyl-pyrrolidone iodine complex and poly-ethyleneoxide/poly-vinyl-pyrrolidone iodine complex as prospective route to antimicrobial wound dressing materials [90]. On the other hand, effects on the early stage wound healing of poly(3-hydroxy butyrate-co-3-hydroxyvalerate) (PHBV) electrospun nanofiber cultured with hair follicular cells were examined by Han et al. [91].

\section{Filtration}

Produced electrospun fibers were specified with attention to their utilization in air filtration by measuring fiber diameter and filtration performance of fiber covering [92]. Fiber filtration is one of the most applicable fields in engineering. For example, media fiber filters have profit of high filtration performance and small air repellent [93, 94]. The performance of filters is related to fiber fineness and it is one of the most significant factors for filters. Electrospinning nano fibers have the ability of catching oil droplets as small as 0.3 $\mu \mathrm{m}$ and this is the important property in filtration industry. So electrospinning fibers are good candidates for removal of unfriendly small particles. The efficiency of electrospun nano fiber filters can be improved based on the wonderful surface area to volume which cause to increase surface cohesion [95]. In 2002 Emig et al. suggested a new method for producing a bag of dust filter including a layer of nano fiber nonwoven [96]. Xiao-Hong Qin et al. measured the fiber diameter, hole diameter, filtration yield as well as filtration repellent of nanofibers texture and sub layers, via a series of tests. The consequences demonstrate that nanofibers diameter is very fine compared with sub-layers. On the other hand, the hole diameter of nanofibers web is very small than sub-layers. Also, the filtration performance and resistance of nanofibers webs are greater than sub-layers [97]. Many studies have reported that electrospun poly-acrylonitrile (PAN) has excellent filtration efficiency [98]. 


\section{Drug delivery}

Electro spinning has been demonstrated as a plain technique for manufacturing polymeric nano scale fibers. Different kinds of artificial and natural polymers have been successfully electro spun into small and fine fibers. The high ratio of surface to volume of produced fibers can increase drug loading and cell attachment attributes. Many kinds of drugs such as antibiotics, anticancer, ribonucleic acid (RNA) and deoxyribonucleic acid (DNA) have been used by electrospun fibers $[99,100]$. Using electrospinning can prepare based capsules nanofiber including drugs to controlling drug delivery system [101-105]. Mami Hamori et al. reported that electrospinning of methacrylic acid copolymer is an effective technique for drug delivery both for polar and non-polar drugs [102]. Toncheva et al. compared the dual spinneret electrospinning and single spinneret electrospinning using poly(L-lactide) as base fibrous, and diclofenac sodium (DS) and lidocaine hydrochloride (LHC) as drug contain. They observed that the dual spinneret approach allowed the ionic action and reaction between diclofenac sodium and lidocaine hydrochloride to be resolved [106].

\section{Conclusion}

Electrospinning is a simple method to produce nano scale fibers both in laboratory and industrially. Because of its wide application such as medicine, filtration, textile, etc. this technique has become one of the most acceptable methods for producing nano fibers. In the last decade the number of researches about this method and its applications has increased and this demonstrates the importance of electrospinning.

Open Access This article is distributed under the terms of the Creative Commons Attribution 4.0 International License (http://crea tivecommons.org/licenses/by/4.0/), which permits unrestricted use, distribution, and reproduction in any medium, provided you give appropriate credit to the original author(s) and the source, provide a link to the Creative Commons license, and indicate if changes were made.

\section{References}

1. Cooley, J.F.: Apparatus for electrically dispersing fluids, 692631

2. Morton, W.J.: Method of dispersing fluids, 705691

3. Formhals, A.: Method and apparatus for spinning, 2349950

4. Formhals, A.: Electro spinning of submicron diameter polymer filaments, 7086846

5. Formhals, A.: Electric field propagating grid for inducing beneficial physiological effects in animals, 3840020

6. Formhals, A.: Preparation and characterization of polymer nano fibres produced from electrospinning, 2077373

7. Harttig, H.: Test element with nanofibers, 7815855

8. Taylor, G.: Disintegration of water drops in an electric field. Proc. R. Soc. Lond. Ser. A Math. Phys. Sci. 280(1382), 383-397 (1964)
9. Taylor, G.: The force exerted by an electric field on a long cylindrical conductor. Proc. R. Soc. Lond. Ser. A Math. Phys. Sci. 291(1425), 145-158 (1966)

10. Taylor, G.: Electrically driven jets. Proc. R. Soc. Lond. Ser. A Math. Phys. Sci. 313(1515), 453-475 (1969)

11. Kim, J.S., Reneker, D.H.: Polybenzimidazole nanofiber produced by electrospinning. Polym. Eng. Sci. 39(5), 849-854 (1999)

12. Fang, X., Reneker, D.H.: DNA fibers by electrospinning. J. Macromol. Sci. Part B 36(2), 169-173 (1997)

13. Darrell, H.R., Iksoo, C.: Nanometre diameter fibres of polymer, produced by electrospinning. Nanotechnology 7(3), 216 (1996)

14. Srinivasan, G., Reneker, D.H.: Structure and morphology of small diameter electrospun aramid fibers. Polym. Int. 36(2), 195-201 (1995)

15. Doshi, J., Reneker, D.H.: Electrospinning process and applications of electrospun fibers. J. Electrostat. 35(2-3), 151-160 (1995)

16. Maretschek, S.: Novel techniques for the incorporation of proteins in biodegradable polymeric drug delivery devices for their controlled release. http://archiv.ub.uni-marburg.de/diss/z2009/ 0123 ed. Philipps-Universität Marburg (2009)

17. Shin, Y.M., Hohman, M.M., Brenner, M.P., Rutledge, G.C.: Experimental characterization of electrospinning: the electrically forced jet and instabilities. Polymer 42(25), 09955-09967 (2001)

18. Yarin, A.L., Koombhongse, S., Reneker, D.H.: Bending instability in electrospinning of nanofibers. J. Appl. Phys. 89(5), 3018 (2001)

19. Long, Q., Cai, M., Li, J., Rong, H., Jiang, L.: Improving the electrical catalytic activity of $\mathrm{Pt} / \mathrm{TiO}_{2}$ nanocomposites by a combination of electrospinning and microwave irradiation. J. Nanopart. Res. 13(4), 1655-1662 (2010)

20. Stranger, J., Staiger, M.P., Tucker, N., Kirwan, K.: Effect of charge density on the taylor cone in electrospinning. Solid State Phenom. 151, 54-59 (2009)

21. Kim, H.S., Kim, K., Jin, H.J., Chin, I.J.: Morphological characterization of electrospun nano-fibrous membranes of biodegradable poly(L-lactide) and poly(lactide-co-glycolide). Macromol. Symp 224(1), 145-154 (2005)

22. Liu, H., Hsieh, Y.L.: Ultrafine fibrous cellulose membranes from electrospinning of cellulose acetate. J. Polym. Sci. Part B Polym. Phys. 40(18), 2119-2129 (2002)

23. Kongkhlang, T., Tashiro, K., Kotaki, M., Chirachanchai, S.: Electrospinning as a new technique to control the crystal morphology and molecular orientation of polyoxymethylene nanofibers. J. Am. Chem. Soc. 130(46), 15460-15466 (2008)

24. Theron, A., Zussman, E., Yarin, A.L.: Electrostatic field-assisted alignment of electrospun nanofibres. Nanotechnology 12(3), 384 (2001)

25. Katta, P., Alessandro, M., Ramsier, R.D., Chase, G.G.: Continuous electrospinning of aligned polymer nanofibers onto a wire drum collector. Nano Lett. 4(11), 2215-2218 (2004)

26. Dersch, R., Liu, T., Schaper, A.K., Greiner, A., Wendorff, J.H.: Electrospun nanofibers: internal structure and intrinsic orientation. J. Polym. Sci. Part A Polym. Chem. 41(4), 545-553 (2003)

27. Xu, C.Y., Inai, R., Kotaki, M., Ramakrishna, S.: Aligned biodegradable nanofibrous structure: a potential scaffold for blood vessel engineering. Biomaterials 25(5), 877-886 (2004)

28. Mathew, G., Hong, J.P., Rhee, J.M., Lee, H.S., Nah, C.: Preparation and characterization of properties of electrospun poly(butylene terephthalate) nanofibers filled with carbon nanotubes. Polym. Test. 24(6), 712-717 (2005)

29. Fennessey, S.F., Farris, R.J.: Fabrication of aligned and molecularly oriented electrospun polyacrylonitrile nanofibers 
and the mechanical behavior of their twisted yarns. Polymer 45(12), 4217-4225 (2004)

30. Huang, Z.M., Zhang, Y.Z., Kotaki, M., Ramakrishna, S.: A review on polymer nanofibers by electrospinning and their applications in nanocomposites. Compos. Sci. Technol. 63(15), 2223-2253 (2003)

31. Wong, S.-C., Baji, A., Leng, S.: Effect of fiber diameter on tensile properties of electrospun poly( $\varepsilon$-caprolactone). Polymer 49(21), 4713-4722 (2008)

32. Teo, W.E., Ramakrishna, S.: Electrospun fibre bundle made of aligned nanofibres over two fixed points. Nanotechnology 16(9), 1878 (2005)

33. Teo, W.E., Ramakrishna, S.: A review on electrospinning design and nanofibre assemblies. Nanotechnology 17(14), R89 (2006)

34. Kim, K., Lee, K., Khil, M., Ho, Y., Kim, H.: The effect of molecular weight and the linear velocity of drum surface on the properties of electrospun poly(ethylene terephthalate) nonwovens. Fibers Polym. 5(2), 122-127 (2004)

35. Yee, W.A., Nguyen, A.C., Lee, P.S., Kotaki, M., Liu, Y., Tan, B.T., Mhaisalkar, S., Lu, X.: Stress-induced structural changes in electrospun polyvinylidene difluoride nanofibers collected using a modified rotating disk. Polymer 49(19), 4196-4203 (2008)

36. Carpinteria, C.A.: Spotlight on wound-care technologies. MPMN. 26(5), (2010)

37. Deitzel, J.M., Kleinmeyer, J., Harris, D., Tan, N.C.B.: The effect of processing variables on the morphology of electrospun nanofibers and textiles. Polymer 42(1), 261-272 (2001)

38. Megelski, S., Stephens, J.S., Chase, D.B., Rabolt, J.F.: Microand nanostructured surface morphology on electrospun polymer fibers. Macromolecules 35(22), 8456-8466 (2002)

39. Baumgarten, P.K.: Electrostatic spinning of acrylic microfibers. J. Colloid Interface Sci. 36(1), 71-79 (1971)

40. Buchko, C.J., Chen, L.C., Shen, Y., Martin, D.C.: Processing and microstructural characterization of porous biocompatible protein polymer thin films. Polymer 40(26), 7397-7407 (1999)

41. Eda, G., Shivkumar, S.: Bead structure variations during electrospinning of polystyrene. J. Mater. Sci. 41(17), 5704-5708 (2006)

42. Tao, J., Shivkumar, S.: Molecular weight dependent structural regimes during the electrospinning of PVA. Mater. Lett. 61(11-12), 2325-2328 (2007)

43. Fridrikh, S.V., Yu, J.H., Brenner, M.P., Rutledge, G.C.: Controlling the fiber diameter during electrospinning. Phys. Rev. Lett. 90(14), 144502 (2003)

44. Fong, H., Liu, W., Wang, C.S., Vaia, R.A.: Generation of electrospun fibers of nylon 6 and nylon 6-montmorillonite nanocomposite. Polymer 43(3), 775-780 (2002)

45. Wang, M., Singh, H., Hatton, T.A., Rutledge, G.C.: Field-responsive superparamagnetic composite nanofibers by electrospinning. Polymer 45(16), 5505-5514 (2004)

46. Li, N., Hui, Q., Xue, H., Xiong, J.: Electrospun polyacrylonitrile nanofiber yarn prepared by funnel-shape collector. Mater. Lett. 79, 245-247 (2012)

47. Zohoori, S., Karimi, L., Ayaziyazdi, S.: A novel durable photoactive nylon fabric using electrospun nanofibers containing nanophotocatalysts. J. Ind. Eng. Chem. 20(5), 2934-2938 (2014)

48. Ayaziyazdi, S., Zohoori, S., Davodiroknabadi, A., Karimnejad, M.: Electrospinning of polyamide fiber containing nano $\mathrm{TiO}_{2}$ and the effect of heat, setting on self-cleaning. Orient. J. Chem. 29(2), 427-443 (2013)

49. Davodiroknabadi, A., L.M., Zohoori, S., Shahrabi, S.: Coating of PA fabric using nano $\mathrm{TiO}_{2}$ by electrospinning of nano fibers. Paper presented at the 11th World textile Conference Autex Mulhouse, France

50. Caruso, R.A., Schattka, J.H., Greiner, A.: Titanium dioxide tubes from sol-gel coating of electrospun polymer fibers. Adv. Mater. 13(20), 1577-1579 (2001)
51. Flemming, R.G., Murphy, C.J., Abrams, G.A., Goodman, S.L., Nealey, P.F.: Effects of synthetic micro- and nano-structured surfaces on cell behavior. Biomaterials 20(6), 573-588 (1999)

52. Ohkawa, K., Minato, K.I., Kumagai, G., Hayashi, S., Yamamoto, H.: Chitosan nanofiber. Biomacromolecules 7(11), 3291-3294 (2006)

53. Schiffman, J.D., Schauer, C.L.: One-step electrospinning of cross-linked chitosan fibers. Biomacromolecules 8(9), 2665-2667 (2007)

54. Min, B.M., Lee, G., Kim, S.H., Nam, Y.S., Lee, T.S., Park, W.H.: Electrospinning of silk fibroin nanofibers and its effect on the adhesion and spreading of normal human keratinocytes and fibroblasts in vitro. Biomaterials 25(7-8), 1289-1297 (2004)

55. Soffer, L., Wang, X., Zhang, X., Kluge, J., Dorfmann, L., Kaplan, D.L., Leisk, G.: Silk-based electrospun tubular scaffolds for tissue-engineered vascular grafts. J. Biomater. Sci. Polym. Ed. 19(5), 653-664 (2008)

56. Huang, L., Nagapudi, K., Apkarian, R.P., Chaikof, E.L.: Engineered collagen-PEO nanofibers and fabrics. J. Biomater. Sci. Polym. Ed. 12(9), 979-993 (2001)

57. Telemeco, T.A., Ayres, C., Bowlin, G.L., Wnek, G.E., Boland, E.D., Cohen, N., Baumgarten, C.M., Mathews, J., Simpson, D.G.: Regulation of cellular infiltration into tissue engineering scaffolds composed of submicron diameter fibrils produced by electrospinning. Acta Biomater. 1(4), 377-385 (2005)

58. Shields, K.J., Beckman, M., Bowlin, G.L., Wayne, J.S.: Mechanical properties and cellular proliferation of electrospun collagen type II. Tissue Eng. 10(9-10), 1510-1517 (2004)

59. Matthews, J.A., Wnek, G., Simpson, D.G., Bowlin, G.L.: Electrospinning of collagen nanofibers. Biomacromolecules 3, 232-238 (2002)

60. Zeugolis, D.I., Khew, S.T., Yew, E.S.Y., Ekaputra, A.K., Tong, Y.W., Yung, L.Y.L., Hutmacher, D.W., Sheppard, C., Raghunath, M.: Electro-spinning of pure collagen nano-fibres-just an expensive way to make gelatin? Biomaterials 29(15), 2293-2305 (2008)

61. Li, M., Mondrinos, M., Chen, X., Gandhi, M.R., Ko, F.K., Lelkes, P.I.: Co-electrospun poly(lactide-co-glycolide), gelatin, and elastin blends for tissue engineering scaffolds. J. Biomed. Mater. Res. A 79(4), 963-973 (2006)

62. Kim, H.W., Song, J.H., Kim, H.E.: Nanofiber generation of gelatin-hydroxyapatite biomimetics for guided tissue regeneration. Adv. Funct. Mater. 15(12), 1988-1994 (2005)

63. Liu, H., Ding, X., Zhou, G., Li, P., Wei, X., Fan, Y.: Electrospinning of nanofibers for tissue engineering applications. J. Nanomater. 2013, 11 (2013)

64. Thostenson, E.T., Ren, Z., Chou, T.W.: Advances in the science and technology of carbon nanotubes and their composites: a review. Compos. Sci. Technol. 61(13), 1899-1912 (2001)

65. Karimi, L., Yazdanshenas, M.E., Khajavi, R., Rashidi, A., Mirjalili, M.: Using graphene/ $/ \mathrm{TiO}_{2}$ nanocomposite as a new route for preparation of electroconductive, self-cleaning, antibacterial and antifungal cotton fabric without toxicity. Cellulose 21(5), 3813-3827 (2014)

66. Karimi, L., Yazdanshenas, M.E., Khajavi, R., Rashidi, A., Mirjalili, M.: Optimizing the photocatalytic properties and the synergistic effects of graphene and nano titanium dioxide immobilized on cotton fabric. Appl. Surf. Sci. 332, 665-673 (2015)

67. Mirjalili, M., Karimi, L.: Preparation of melt spun electroconductive fine fibres containing carbon nanotubes. Autex Res. J. 15(2), 87-92 (2015)

68. Lau, A.K.T., Hui, D.: The revolutionary creation of new advanced materials-carbon nanotube composites. Compos. B Eng. 33(4), 263-277 (2002) 
69. Park, C., Ounaies, Z., Watson, K.A., Pawlowski, K., Lowther, S.E., Connell, J.W., Siochi, E.J., Harrison, J.S., Clair, T.L.S.: Polymer-single wall carbon nanotube composites for potential spacecraft applications. MRS Online Proc. Libr. 706, 11 (2001)

70. Jiang, Q., Fu, G., Xie, D., Jiang, S., Chen, Z., Huang, B., Zhao, Y.: Preparation of carbon nanotube/polyaniline nanofiber by electrospinning. Procedia Eng. 27, 72-76 (2012)

71. Maitra, T., Sharma, S., Srivastava, A., Cho, Y.K., Madou, M., Sharma, A.: Improved graphitization and electrical conductivity of suspended carbon nanofibers derived from carbon nanotube/ polyacrylonitrile composites by directed electrospinning. Carbon 50(5), 1753-1761 (2012)

72. Mazinani, S., Ajji, A., Dubois, C.: Fundamental study of crystallization, orientation, and electrical conductivity of electrospun PET/carbon nanotube nanofibers. J. Polym. Sci. Part B Polym. Phys. 48(19), 2052-2064 (2010)

73. Rana, S., Cho, J.: Core-sheath polyurethane-carbon nanotube nanofibers prepared by electrospinning. Fibers Polym. 12(6), 721-726 (2011)

74. Angadjivand, S.A., Schwartz, M.G., Eitzman, P.D., Jones, M.E.: Method and apparatus for making a nonwoven fibrous electret web from free-fiber and polar liquid. In. Google Patents, (2002)

75. Gibson, P.W., Schreuder-Gibson, H.L., Rivin, D.: Electrospun fiber mats: transport properties. AIChE J. 45(1), 190-195 (1999)

76. Fertala, A., Han, W.B., Ko, F.K.: Mapping critical sites in collagen II for rational design of gene-engineered proteins for cell-supporting materials. J. Biomed. Mater. Res. 57(1), 48-58 (2001)

77. Jin, H.J., Fridrikh, S.V., Rutledge, G.C., Kaplan, D.L.: Electrospinning Bombyx mori silk with poly(ethylene oxide). Biomacromolecules 3(6), 1233-1239 (2002)

78. Nain, A.S., Phillippi, J.A., Sitti, M., MacKrell, J., Campbell, P.G., Amon, C.: Control of cell behavior by aligned micro/nanofibrous biomaterial scaffolds fabricated by spinneretbased tunable engineered parameters (STEP) technique. Small 4(8), 1153-1159 (2008)

79. Sun, T., Norton, D., Vickers, N.L., McArthur, S., Neil, S.M., Ryan, A.J., Haycock, J.W.: Development of a bioreactor for evaluating novel nerve conduits. Biotechnol. Bioeng. 99(5), 1250-1260 (2008)

80. Bini, T.B., Gao, S., Wang, S., Ramakrishna, S.: Poly(L-lactideco-glycolide) biodegradable microfibers and electrospun nanofibers for nerve tissue engineering: an in vitro study. J. Mater. Sci. 41(19), 6453-6459 (2006)

81. Theron, A., Zussman, E., Yarin, A.L.: Electrostatic field-assisted alignment of electrospun nanofibers. Nanotechnology 12, 384-390 (2001)

82. Li, D., Wang, Y., Xia, Y.: Electrospinning of polymeric and ceramic nanofibers as uniaxially aligned arrays. Nano Lett. 3, 1167-1171 (2003)

83. Coffee, R.A.: A dispensing device and method for forming material. In. Google Patents, (1998)

84. Khanam, N., Mikoryak, C., Draper, R.K., Balkus Jr, K.J.: Electrospun linear polyethyleneimine scaffolds for cell growth. Acta Biomater. 3(6), 1050-1059 (2007)

85. Chen, J.P., Chang, G.Y., Chen, J.K.: Electrospun collagen/chitosan nanofibrous membrane as wound dressing. Colloids Surf. A 313-314, 183-188 (2008)

86. Liang, D., Hsiao, B.S., Chu, B.: Functional electrospun nanofibrous scaffolds for biomedical applications. Adv. Drug Deliv. Rev. 59(14), 1392-1412 (2007)

87. Hong, K.H.: Preparation and properties of electrospun poly(vinyl alcohol)/silver fiber web as wound dressings. Polym. Eng. Sci. 47(1), 43-49 (2007)

88. Duan, Y.Y., Jia, J., Wang, S.H., Yan, W., Jin, L., Wang, Z.Y.:

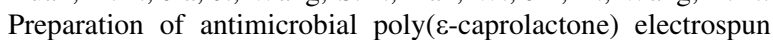

nanofibers containing silver-loaded zirconium phosphate nanoparticles. J. Appl. Polym. Sci. 106(2), 1208-1214 (2007)

89. Kim, G.H., Yoon, H.: A direct-electrospinning process by combined electric field and air-blowing system for nanofibrous wound-dressings. Appl. Phys. A 90(3), 389-394 (2008)

90. Ignatova, M., Manolova, N., Rashkov, I.: Electrospinning of poly(vinyl pyrrolidone)-iodine complex and poly(ethylene oxide)/poly(vinyl pyrrolidone)-iodine complex-a prospective route to antimicrobial wound dressing materials. Eur. Polym. J. 43(5), 1609-1623 (2007)

91. Han, I., Shim, K.J., Kim, J.Y., Im, S.U., Sung, Y.K., Kim, M., Kang, I.-K., Kim, J.C.: Effect of poly(3-hydroxybutyrate-co-3hydroxyvalerate) nanofiber matrices cocultured with hair follicular epithelial and dermal cells for biological wound dressing. Artif. Organs 31(11), 801-808 (2007)

92. Heikkilä, P., Taipale, A., Lehtimäki, M., Harlin, A.: Electrospinning of polyamides with different chain compositions for filtration application. Polym. Eng. Sci. 48(6), 1168-1176 (2008)

93. Sundarrajana, S., Tana, K.L., Lima, S.H., Ramakrishna, S.: Electrospun nanofibers for air filtration applications. Procedia Eng. 75, 159-163 (2014)

94. Tsai, P.P., Schreuder-Gibson, H., Gibson, P.: Different electrostatic methods for making electret filters. J. Electrostat. 54(3-4), 333-341 (2002)

95. Graham, K., Ouyang, M., Raether, T., Grafe, T., McDonald, B., Knauf, P.: Polymeric nanofibers in air filtration applications. Paper presented at the Fifteenth Annual Technical Conference \& Expo of the American Filtration \& Separations Society, Galveston, Texas, April 9-12

96. Emig, D., Klimmek, A., Raabe, E.: Dust filter bag containing nano non-woven tissue, 6395046

97. Qin, X.H., Wang, S.Y.: Filtration properties of electrospinning nanofibers. J. Appl. Polym. Sci. 102(2), 1285-1290 (2006)

98. Kim, K., Lee, C., Kim, I., Kim, J.: Performance modification of a melt-blown filter medium via an additional nano-web layer prepared by electrospinning. Fibers Polym. 10(1), 60-64 (2009)

99. Hu, X., Liu, S., Zhou, G., Huang, Y., Xie, Z., Jing, X.: Electrospinning of polymeric nanofibers for drug delivery applications. J. Control. Release 185, 12-21 (2014)

100. Sill, T.J., von Recum, H.A.: Electrospinning: applications in drug delivery and tissue engineering. Biomaterials 29(13), 1989-2006 (2008)

101. Rogina, A.: Electrospinning process: versatile preparation method for biodegradable and natural polymers and biocomposite systems applied in tissue engineering and drug delivery. Appl. Surf. Sci. 296, 221-230 (2014)

102. Hamori, M., Yoshimatsu, S., Hukuchi, Y., Shimizu, Y., Fukushima, K., Sugioka, N., Nishimura, A., Shibata, N.: Preparation and pharmaceutical evaluation of nano-fiber matrix supported drug delivery system using the solvent-based electrospinning method. Int. J. Pharm. 464(1-2), 243-251 (2014)

103. Yu, D.G., Chian, W., Wang, X., Li, X.Y., Li, Y., Liao, Y.Z.: Linear drug release membrane prepared by a modified coaxial electrospinning process. J. Membr. Sci. 428, 150-156 (2013)

104. Xu, L., He, J.H., Wang, L.: Drug-loaded nano materials by electrospinning. Curr. Opin. Biotechnol. 22S, S15-S152 (2011)

105. Savva, I., Constantinou, D., Evaggelou, L., Marinica, O.M., Taculescu, A., Vekas, L.: PEO/PLLA and PVP/PLLA-based magnetoresponsive nanocomposite membranes: fabrication via electrospinning, characterization and evaluation in drug delivery. Procedia Eng. 44, 1052-1053 (2012)

106. Toncheva, A., Paneva, D., Manolova, N., Rashkov, I., Mita, L., Crispi, S., Damiano, G.M.: Dual vs. single spinneret electrospinning for the preparation of dual drug containing non-woven fibrous materials. Colloids Surf. A 439, 176-183 (2013) 